\title{
A comparison of oral narratives in children with specific language and non-specific language impairment
}

\author{
WENDY M. PEARCE ${ }^{1}$, DEBORAH G. H. JAMES ${ }^{2}$, \& PAULF. MCCORMACK ${ }^{3}$ \\ ${ }^{1}$ Fames Cook University, Queensland, Australia, ${ }^{2}$ The University of Adelaide, South Australia, and \\ ${ }^{3}$ Flinders University, South Australia
}

(Received 30 March 2009; Accepted 26 February 2010)

\begin{abstract}
This research investigated whether children with specific language impairment (SLI) and non-specific language impairment (NLI) could be differentiated by their oral narrative characteristics. Oral narrative samples were collected from 69 children and comparisons were made among four groups of participants. The two language impairment groups (SLI and NLI), aged 4;11-6;03, were matched for age and their linguistics skills. Their oral narratives were compared between these diagnostic groups and with agematched and language-matched control groups. Measures of narrative structure, cohesion, and information did not significantly differentiate the SLI and NLI groups, suggesting that the influence of their similar linguistic skills on oral narrative measures was stronger than the influence of their differing non-verbal cognition. The SLI group produced significantly more complex and informative oral narratives than the language-matched group, while the NLI group differed from the language-matched group on fewer measures. Interactions among linguistic, cognitive, maturational, and task factors are discussed.
\end{abstract}

Keywords: specific language impairment, non-specific language impairment, differential diagnosis, oral narrative

\section{Introduction}

While oral narrative deficits are identified as a characteristic of language impairment (LI), few studies have explored differences and similarities among the oral narratives of children with LI who have differing levels of non-verbal cognitive ability. Specific language impairment (SLI) and non-specific language impairment (NLI) are both diagnostic categories that differ primarily on the basis of their non-verbal cognitive abilities. Both SLI and NLI occur in the absence of any known cause or identifiable disorders such as hearing impairments, intellectual disability, neurological disorders, or chromosomal syndromes.

Psychometrically, a LI is defined as language abilities falling below a $z$-score of -1.0 (equivalent to a percentile rank of 16 and a standard score of 85) on a standardized assessment (Watkins, 1994). Children with SLI have non-verbal cognitive abilities in the average or above average range, that is above a $z$-score of -1.0 . Children with NLI have non-verbal

Correspondence: Wendy M. Pearce, Discipline of Speech Pathology, School of Public Health, Tropical Medicine and Rehabilitation Sciences, James Cook University, Townsville QLD 4811, Australia. Tel: 6174781 6501. Fax: 6174772 6868. E-mail: wendy. pearce@jicu.edu.au

ISSN 0269-9206 print/ISSN 1464-5076 online (C) 2010 Informa UK Ltd.

DOI: $10.3109 / 02699201003736403$ 
cognitive abilities below the average range, yet not in the intellectual disability range, therefore below a $z$-score of -1.0 but above a $z$-score of -2.0 (Ellis Weismer, Tomblin, Zhang, Buckwalter, Chynoweth, and Jones, 2000; Rice, Tomblin, Hoffman, Richman, and Marquis, 2004). In clinical contexts the diagnostic divide may be small, with a few points difference in non-verbal IQ placing children in differing diagnostic categories (Casby, 1992). The implications may be significant though, as children with SLI may be provided with more intervention than children with NLI (Department of Education and Children's Services, 1996; Education Queensland, 2003; Dockrell, Lindsay, Letchford, and Mackie, 2006).

Because SLI and NLI ostensibly differ only in their levels of non-verbal cognitive ability, differences in their language characteristics may be attributed to cognitive influences (Ellis Weismer et al., 2000; Fey, Catts, Proctor-Williams, Tomblin, and Zhang, 2004; Rice et al., 2004). Explorations of differences between these two diagnostic groups may contribute to our understanding of how discourse characteristics in LI are influenced by linguistic compared to non-verbal cognitive skills and clarify whether there is value in making diagnostic distinctions between SLI and NLI.

\section{Comparisons between SLI and NLI}

Children with SLI and NLI were shown to have similar morphosyntactic language characteristics in several studies (Pearce, McCormack, and James, 2003; Fey et al., 2004; Rice, et al., 2004). Both diagnostic groups had more errors in the verb phrase than the noun phrase and significant difficulties with finite tense forms.

Two studies compared the oral narratives of children with SLI and NLI (Fey et al., 2004; Pearce et al., 2003). A small study by Pearce et al. found that young children with SLI told more complex stories than children with NLI who were matched for MLU. Yet, the NLI group had a more severe LI as measured by a comprehensive standardized language assessment, so the oral narrative differences could be due to severity of the LI. Conversely, a larger epidemiological study by Fey et al. determined that the narratives of school-aged children with NLI were structurally similar to those of children with SLI for plot, context, and quality components. A group with typically-developing language (TDL) but low non-verbal cognition also produced narratives that were significantly poorer than the age-matched group with TDL, similar to the SLI group and better than the NLI group. This suggests that both nonverbal cognition and linguistic skills play a role in narrative abilities.

\section{Narrative features of SLI}

Oral narrative skills have been well researched in children with SLI, with three primary features of oral narrative identified as problematic: organizational structure, cohesion, and information. Findings differ across studies due to varying methodology across measures, procedures, and ages. School-aged children with SLI produce less mature narrative structures than age-matched children with TDL (Olley, 1989; Paul, Hernandez, Taylor, and Johnson, 1996; Miranda, McCabe, and Bliss, 1998; Wagner, Sahlen, and Nettelbladt, 1999; Manhardt and Rescorla, 2002). School-aged children with SLI produce essential plot components less often (Merritt and Liles, 1987; Olley, 1989; Copmann and Griffith, 1994), and produce fewer quality and context components than age-matched controls, resulting in reporting of less events and less complete episodes (Liles, 1987; Merritt and Liles, 1987; Olley, 1989; Copmann and Griffith, 1994; Gillam and Carlile, 1997). The narrative structures of school-aged children with SLI are more 'confused' than those of 
age-matched children with TDL with omission of critical content, inclusion of irrelevant information, lack of a consistent theme, lack of logical sequence, and omission of a logical consequence or conclusion (Merritt and Liles, 1987; Gillam and Carlile, 1997; Miranda et al., 1998).

In contrast, significant differences for narrative structure were not evident between young children with SLI and age-matched peers for their narrative retells in two studies (Boudreau and Hedberg, 1999; Kaderavek and Sulzby, 2000). Reasons for differing findings across narrative research are complex and varied, and may relate to differing stimuli, elicitation procedures, measures analysed, age, and cultural background (Shapiro and Hudson, 1991; Berman and Slobin, 1994; McCabe and Rollins, 1994; Johnson, 1995; Pearce, 2003). Studies that identified differences in narrative structure examined school-aged children and often used narrative generation tasks, while the two studies that did not identify differences examined younger children and used narrative retell or emergent reading tasks.

Two studies compared the structure of oral narratives between school-aged children with SLI and younger language-matched children with TDL. The children with SLI produced simpler narratives than language-matched groups matched on reading ability or a standardized language assessment (Olley, 1989; Gillam and Carlile, 1997). This suggests that difficulties with narrative structure are a significant deficit or characterize a disordered pattern of development for children with LI. Comparisons between younger children with SLI and a language-matched control group were not evident in the literature.

Children with SLI often have difficulty using appropriate cohesive devices to identify story characters (Liles, 1985; Olley, 1989; Strong and Shaver, 1991; Paul and Smith, 1993; Paul et al., 1996; Kaderavek and Sulzby, 2000; Norbury and Bishop, 2003). They produce proportionally fewer cohesive ties and use more lexical and demonstrative ties and fewer pronominal ties than children with TDL. Their cohesive ties are also less adequate as they produce less complete and more erroneous cohesive ties than age-matched children with TDL. Young children with SLI initially demonstrate difficulties with the pronominal referencing system through ambiguity and incorrect use of pronouns; but, later, their difficulties in the school years are often demonstrated in a preference for lexical ties in place of pronominal ties (van der Lely, 1997; Norbury and Bishop, 2003).

Limited information provision is a problem for children with SLI compared to agematched children with TDL. Information scores tap expressive vocabulary and provide a measure of how well children label characters, objects, locations, and actions. Certain information items may be identified as closely associated with key story event structure, while others bear little relationship to structure and cohesion. In retell tasks with wordless picture books, children with SLI produced significantly less information than their agematched peers (Paul and Smith, 1993; Boudreau and Hedberg, 1999). Conversely, studies of older children have identified similar levels of information provision between children with SLI and age-matched groups in a narrative generation from a wordless picture book and retells of a story after reading it aloud (Gillam and Carlile, 1997; Norbury and Bishop, 2003). Again, it must be noted that methods for eliciting narratives and analysing information provision differed across these studies.

\section{Explanations for narrative deficits in SLI and implications for NLI}

Theoretical explanations for narrative deficits in children with SLI focus largely on linguistic deficits and processing capacity deficits. Linguistic explanations propose that the creation of oral narrative text requires considerable morphosyntactic and lexical resources (Halliday and 
Hasan, 1976; Hemphill, Picardi, and Tager-Flusberg, 1991; Strong and Shaver, 1991; Liles, 1993). Miranda et al. (1998) suggested that cohesion difficulties may arise from difficulties with word retrieval, complex sentence production, and syntactic mastery of pronouns and articles. Cohesion and grammatical accuracy have been identified as better classifiers of SLI vs TDL than measures of narrative structure and clause complexity (Liles, Duffy, Merritt, and Purcell, 1995). Linguistic explanations predict that language-matched groups of children with SLI and NLI will have similar difficulties with the production of informative, grammatical, and cohesive narrative texts. Predictions for narrative structure are less clear.

Norbury and Bishop (2003) also argued that linguistic ability, rather than pragmatic skills, determined narrative competence. They found similar narrative deficits among children with SLI, pragmatic impairment, and high functioning autism, compared to TDL (with all groups matched for non-verbal cognitive ability). All three LI groups had similar levels of receptive and expressive grammatical skills, but the children with pragmatic LI and autism had poorer pragmatic skills than the SLI group.

A limited processing capacity in children with $\mathrm{LI}$ is considered to adversely affect narrative organization (Shapiro and Hudson, 1991; Eaton, Collis, and Lewis, 1999). Episodic memory, which is dependent on processing capacity, is critical for storing and manipulating narrative scripts, information about situations and events, world knowledge, and related feelings, motivations, and beliefs (van Dijk and Kintsch, 1983). The use of cohesive pronouns may be constrained by limitations in working memory or processing capacity in children with LI. The identity of a pronoun referent is retrievable from the prior text while it remains within working memory or must be inferred from the situational context. Pronominal reference may become ambiguous when children are not able to hold identity chains within their working memory. The task of selecting appropriate lexical forms for describing story elements in a narrative task may also be constrained by limitations in working memory. Such difficulties will not be identified in simple vocabulary tests but may be identified in measures of vocabulary use or information provision in narrative tasks.

Children with SLI and NLI have been identified with similar difficulties with verbal working memory, measured by non-word repetition (Ellis Weismer et al., 2000). However, cognitive processes are believed to contribute to the logical organization of narrative events and information, suggesting that children with NLI will have greater difficulties with organizing and structuring logical, well-sequenced narratives (Liles, 1993). Children with NLI may have poorer general or episodic processing skills than children with SLI due to lesser support from intact cognitive processes, suggesting the possibility of greater problems with narrative structure, cohesion, and information provision in NLI.

In addition, developmental and social factors are implicated as explanations for difference and variation in oral narrative skills in children with both LI and TDL. Variation in oral narrative skills has hampered the development of norms, makes research comparisons more complex, and implies that many contributing factors may be at play in the early development of narrative skills (Berman and Slobin, 1994; McCabe and Rollins, 1994; Johnson, 1995). Knowledge about the world and human behaviour are critical for narrative comprehension and production, including knowledge of cause and effect, goals and intentions, beliefs, attitudes, emotions, personality, and social role. Early experiences at home, in early childhood educational contexts, and then school form essential foundations for narrative production: including socio-dramatic play, interactive story-book experiences, recounting daily events, and more formalized story-writing (Eckler and Weininger, 1989; Westby, 1991). Comparisons between school-aged children with SLI and younger language-matched controls, described earlier, showed that linguistic deficits overrode any advantages of experience with oral narratives in the older children (Olley, 1989; Gillam and Carlile, 1997). The interplay of these factors (linguistic ability and experience) for 
younger children with SLI is not well researched. It is possible that children with NLI may be less well equipped than children with SLI to take advantage of their experience with oral narratives due to their poorer cognitive skills.

\section{Purpose}

In summary, the literature shows that school-aged children with SLI have poorer narrative structure and cohesion than their age-matched peers, yet similar information provision. They also produce poorer narratives than language-matched controls. Younger children with SLI are shown to have poorer cohesion and information provision than age-matched peers, yet perform similarly on measures of narrative structure. This suggests that, in the early stages of narrative development, poor grammatical and lexical skills in young children with SLI have significant impact on cohesion and information but less measurable impact on narrative structure. This is consistent with the finding that cohesion and grammatical accuracy are better identifiers of SLI than narrative structure (Liles et al., 1995). Findings from a small set of studies vary on whether children with NLI show similar oral narrative features to SLI.

The primary purpose of this research is to explore whether oral narrative characteristics can differentiate SLI from NLI. Previously, comparative studies of children with SLI and NLI have used epidemiologically ascertained samples (Tomblin and Zhang, 1999; Fey et al., 2004; Rice et al., 2004), longitudinal comparisons (Stothard, Snowling, Bishop, Chipchase, and Kaplan, 1998; Fey, et al., 2004), and twin comparisons (Bishop, 1994). Comparisons using close matching on a limited set of language variables are not apparent in the literature. Such comparisons will enable closer analysis of qualitative differences in language profiles and may differentiate disordered patterns of development from delay patterns. This method has often been used to explore grammatical differences in LI (e.g. Leonard, Eyer, Bedore, and Grela, 1997; Rice, Wexler, Marquis, and Hershberger, 2000).

If the oral narratives of children with NLI are poorer than those of children with SLI, this will suggest that oral narrative skills are influenced by non-verbal cognitive skills. Such differences may form differential diagnostic markers. In contrast, a finding of no differences will suggest that oral narrative skills are more dependant on underlying linguistic abilities and that diagnostic distinctions between SLI and NLI are not useful. School-aged children with SLI have been shown to produce simpler narratives than younger language-matched controls. If a younger language-matched group also differs from the SLI and/or NLI groups, this may have implications for the influential strength of linguistic, cognitive, and life experience factors.

Specific questions to be answered by this research are:

(1) Do children with SLI and NLI differ significantly on measures of oral narrative structure, content, and cohesion?

(2) Do the key oral narrative features of SLI and NLI differ significantly from younger language-matched children with TDL, as well as from age-matched children?

\section{Method}

\section{Participants}

Recruitment. Thirty-four children with LI aged from 5;0-6;3 years were recruited from speech pathology caseloads in South Australian pre-schools and schools. All had moderate-to-severe LI, consistent with state-wide service delivery priorities (Department of Education and Children's 
Services, 1996), and no history of persistent hearing impairments, neurological disorders, syndromes, chromosomal disorders, autism, or socio-emotional disorders. Children with speech impairments and from non-English speaking or Aboriginal English speaking backgrounds were excluded. A diagnosis of expressive LI was confirmed using the Clinical Evaluation of Language Fundamentals - Preschool (CELF-P) (Wiig, Secord, and Semel, 1993), with the $10^{\text {th }}$ percentile on the Expressive Language Score as criterion level (equivalent to a standard deviation of -1.25) (Leonard, 1998; Haynes and Pindzola, 2008). All testing for inclusionary and exclusionary criteria, and for the dependent variables, was administered by the first author and took up to 2 hours for each participant, spread over two-to-three sessions, 1-2 weeks apart.

Non-verbal ability criteria. A screening measure of non-verbal cognitive ability, the Raven's Coloured Progressive Matrices (RCPM) (Raven, Court, and Raven, 1995), was administered to all children. A raw score of 10 (equating to the $10^{\text {th }}$ percentile for 5.5 year-old children) was used as the upper cut-off score for differentiation into the NLI group and a raw score of 13 (equating to the $25^{\text {th }}$ percentile) as the lower cut-off score for differentiation into the SLI group. Reports for comprehensive intelligence assessments were available for 24 children: the Wechsler Preschool and Primary Scale of Intelligence Revised (Wechsler, 1989); the Differential Ability Scales (Elliott, 1990); or the Wechsler Intelligence Scale for Children III (Wechsler, 1992). Seven participants attained RCPM scores ranging from 10-13 (10-25 ${ }^{\text {th }}$ percentiles for 5.5 year olds), and results from the more comprehensive cognitive assessments placed six children in the NLI group and one child in the SLI group, using the standard diagnostic cut-off of the $16^{\text {th }}$ percentile (or $z$-score of -1.0 ). There was $100 \%$ agreement between the RCPM and available comprehensive cognitive assessments for differentiation into the SLI and NLI groups for the other 17 children.

Language matching. Statistical analysis of the participant variables was conducted using a $t$-test and a significance level of $p<.05$, adjusted for six pairwise comparisons using the Holm method to counteract risk of Type 1 errors (Aickin and Gensler, 1996). An initial examination of the CELF-P results revealed a significant difference between the SLI and NLI groups on the Expressive Language scale for the children referred $(z=-2.916, p=.003)$, with the SLI group having less severe language impairments than the NLI group. Therefore, six children with Expressive Language standard scores above 75 (percentile rank above 5) were excluded from the SLI group. This resulted in 15 participants in the SLI diagnostic group matched with 13 in the NLI group on their CELF-P Expressive and Receptive Language scores $(p>.05)$.

MLU was calculated for all participants from a play-based conversational language sample using complete and intelligible utterances, with the exclusion of yes, no, and okay responses. This exclusion controlled for any discourse influences that may have been imposed by the researcher. The conversation samples (of at least 50 utterances) were elicited during a 20 minute play session using a standard set of toys, extended to 30 minutes for several children who talked little. Inter-rater reliability agreement for analysis of $10 \%$ of the conversation samples was good: $98.5 \%$ for utterance boundaries and $88.3 \%$ for morpheme-to-morpheme transcription. The reliability checks were performed by an independent speech pathologist experienced in transcription and differences were resolved by consensus.

Control groups. Twenty-one children with TDL aged from 4;11-5;11 years were recruited from pre-schools and schools in the same geographical areas as the LI groups to form an age-matched control group (AM). Twenty children with TDL aged from 2;7-3;6 years were recruited from the same geographical area, to form a control group matched on language ability (LM). 
The RCPM was administered to children in the two control groups with a manipulative form of the RCPM used with the younger LM group. The AM group was required to have non-verbal abilities within the normal range $\left(\geq 25^{\text {th }}\right.$ percentile) which was confirmed with this assessment. It was anticipated that raw scores from the RCPM for the LM group may be illuminating for post-hoc analysis, even though norms were not available for the younger LM group. The RCPM raw scores were interpreted within broad percentile rank ranges in the manual $\left(10^{\text {th }}, 25^{\text {th }}, 50^{\text {th }}\right.$, etc $)$ and for broad age ranges, so descriptive statistics for the RCPM are presented more readily as raw scores for group comparisons.

All AM and LM participants were required to have language abilities in the normal range (> $16^{\text {th }}$ percentile). To confirm this, the CELF-P was administered to the AM group. The LM participants were assessed using the Reynell Developmental Language Scales 3 (RDLS) (Edwards, Fletcher, Garman, Hughes, Letts, and Sinka, 1997) since the CELF-P was not appropriate for the younger children.

Participant characteristics. All participant characteristics are shown in Table I. There were no significant differences between the final SLI and NLI groups for their language abilities, measured using the CELF-P and MLU. There was also no significant difference between the LM group and the SLI and NLI groups for MLU, indicating that they were matched for their grammatical abilities. The AM group's CELF-P Receptive, Expressive, and Language standard scores were significantly higher than the SLI and NLI groups $(p<.001)$ and the MLU of the AM group was significantly higher than the remaining groups $(p<.001)$. The SLI, NLI, and AM groups were matched for age.

The SLI group's RCPM scores were significantly higher than the NLI group $(p<.001)$, as expected. While the NLI and LM groups were matched for RCPM scores, the AM group's RCPM scores were significantly higher than the SLI group $(p<.05)$. The lack of matching between the SLI and AM groups was not considered a difficulty for the main purpose of this research, to explore language differences between the two diagnostic groups, SLI and NLI.

Table I. Participant and group characteristics: showing means, standard deviations, and ranges for age, language, and non-verbal cognitive ability results.

\begin{tabular}{lcrrrr}
\hline & & \multicolumn{4}{c}{ Group } \\
\cline { 3 - 6 } Variable & Measure & SLI & NLI & AM & LM \\
\cline { 3 - 6 } Total $(n)$ & $n$ & 15 & 13 & 21 & 20 \\
Male $(n)$ & $n$ & 9 & 7 & 11 & 10 \\
Female $(n)$ & $n$ & 6 & 6 & 10 & 10 \\
Age (mths) & $M(S D)$ & $65.1(4.5)$ & $66.7(5.5)$ & $66.5(3.5)$ & $36.2(4.0)$ \\
& Range & $60-74$ & $59-74$ & $59-71$ & $30-41$ \\
MLU (morphemes) & $M(S D)$ & $3.61(.66)$ & $3.63(.69)$ & $5.05(.72)$ & $3.95(.76)$ \\
& Range & $2.64-4.50$ & $2.37-4.56$ & $3.80-6.65$ & $2.89-5.05$ \\
Expressive language percentile ranks & $M(S D)$ & $2.8^{a}(1.6)$ & $1.7^{a}(1.3)$ & $49^{a}(18.9)$ & $60.6^{b}(27.0)$ \\
& Range & $1-5$ & $1-5$ & $21-93$ & $17-96$ \\
Receptive language percentile ranks & $M(S D)$ & $6.4^{a}(11.2)$ & $5.9^{a}(9.2)$ & $69.3^{a}(19.1)$ & $58.7^{b}(22.5)$ \\
& Range & $1-39$ & $1-32$ & $32-98$ & $21-92$ \\
RCPM ${ }^{c}$ raw score & $M(S D)$ & $16.8(3.2)$ & $9.1(2.9)$ & $19.6(3.6)$ & $8.2(4.4)$ \\
& Range & $13-24$ & $2-13$ & $14-27$ & $0-17$ \\
\hline
\end{tabular}

${ }^{a}$ CELF-P percentiles; ${ }^{b}$ Reynell Developmental Language Scales III percentiles; ${ }^{c}$ Raven's Coloured Progressive Matrices. 
Linguistic skills. The conversational samples (used for determining MLU) were further analysed for grammatical accuracy and syntactic complexity (Pearce, 2006). These were not matching requirements, but revealed further information about the linguistic abilities of the participants. Inter-rater reliability agreement for point-to-point grammatical coding was $97.4 \%$ (using checks of $10 \%$ of samples by an independent speech pathologist). Grammatical accuracy measures analysed were finite tense accuracy (regular past tense, third person singular, tense auxiliaries, and copula), non-tense morpheme accuracy (continuous aspect 'ing' and the modal auxiliaries), and noun phrase morpheme accuracy (articles, plurals, and possessives). Measures of syntactic complexity were the percentage of verbal utterances classified as fragments and complex utterances (two or more-clauses).

There were no significant differences between the SLI, NLI, and LM groups for grammatical accuracy or syntactic complexity, but all these groups achieved significantly lower accuracy $(p \leq .001)$ and complexity measures $(p \leq .01)$ than the AM group. These results are shown in Table II, while significance and effect sizes are shown in Table III. Effect sizes

Table II. Results for grammatical accuracy (percentage correct) and syntactic complexity (percentage of utterances) for the conversational samples, reported as medians.

\begin{tabular}{lrrrr}
\hline & \multicolumn{3}{c}{ Group } \\
\cline { 2 - 5 } Variable & \multicolumn{1}{c}{ SLI } & NLI & AM & LM \\
\hline Finite Tense Composite & $67(23)$ & $49(44)$ & $91(9)$ & $67(25)$ \\
Non-finite Verb Composite & $73(24)$ & $77(27)$ & $98(3)$ & $86(23)$ \\
Noun Phrase Composite & $82(14)$ & $37(50)$ & $95(7)$ & $88(16)$ \\
Fragments & $29(15)$ & $6(11)$ & $33(22)$ \\
Complex Utterances & $4(7)$ & & $11(6)$ & $5(8)$ \\
\hline
\end{tabular}

Interquartile ranges are presented in parentheses.

Table III. Significance levels and effect sizes for pairwise comparisons for grammatical accuracy and syntactic complexity.

\begin{tabular}{|c|c|c|c|c|c|c|c|}
\hline \multirow[b]{3}{*}{ Measure } & \multirow[b]{3}{*}{ Value } & \multicolumn{6}{|c|}{ Group comparisons } \\
\hline & & \multirow{2}{*}{$\begin{array}{c}\text { LI } \\
\text { NLI-SLI }\end{array}$} & \multicolumn{2}{|c|}{ LI \& LM } & \multicolumn{2}{|c|}{$\mathrm{LI} \& \mathrm{AM}$} & \multirow{2}{*}{$\begin{array}{c}\text { TDL } \\
\text { LM-AM }\end{array}$} \\
\hline & & & NLI-LM & SLI-LM & NLI-AM & SLI-AM & \\
\hline \multirow[t]{2}{*}{ Finite tense composite } & $p$ & .093 & .187 & .960 & $<.001$ & $<.001$ & $<.001$ \\
\hline & $r$ & & & & .67 & .78 & .73 \\
\hline \multirow[t]{2}{*}{ Non-finite verb composite } & $p$ & .427 & .213 & .107 & $<.001$ & $<.001$ & $<.001$ \\
\hline & $r$ & & & & .78 & .74 & .75 \\
\hline \multirow[t]{2}{*}{ Noun phrase composite } & $p$ & .466 & .130 & .561 & .001 & $<.001$ & $<.001$ \\
\hline & $r$ & & & & .54 & .58 & .53 \\
\hline \multirow[t]{2}{*}{ Fragments } & $p$ & .333 & .316 & 1.000 & $<.001$ & $<.001$ & .002 \\
\hline & $r$ & & & & .58 & .56 & .48 \\
\hline \multirow[t]{2}{*}{ Complex utterances } & $p$ & .386 & .638 & .517 & .009 & $<.001$ & .001 \\
\hline & $r$ & & & & .45 & .57 & .49 \\
\hline
\end{tabular}

Effect sizes are presented for significant comparisons as the co-efficient $(r=z / \sqrt{n})$; see Table IV for explanation of Holm adjusted significance levels. The group comparisons are clustered, from left to right: $\mathrm{LI}=$ comparison between the SLI and NLI groups; LI \& LM = comparisons between the LM group and each LI group; LI \& AM = comparisons between the AM group and each LI group; TDL = comparison between the AM and LM groups. 
for differences between the AM and other groups were large for grammatical accuracy and moderate-to-large for the percentage of complex clauses.

\section{Procedures}

Two oral narratives were elicited using problem-based picture stimuli. Problem-based stimuli present a problem than requires a solution and are considered best practice for eliciting a goal-directed narrative focused on resolution of a problem (Shapiro and Hudson, 1991). Picture stimuli are commonly recommended for eliciting narratives from young children (Hughes, McGillivray, and Schmidek, 1997), although there is limited information available about the age or stage where it becomes more discriminating to provide less visual support (Wellhousen, 1993; Spinillo and Pinto, 1994). A generation strategy was chosen in preference to a re-tell strategy for both narratives because it was believed to be a more demanding procedure and therefore more likely to elicit differences between the SLI and NLI groups (Eaton et al., 1999; Pearce, 2003). The sequence of administration was alternated across participants to reduce the impact of any order effects. For both narratives, the examiner did not provide any evaluative comments, but showed interest and encouragement through nonverbal responses such as 'mm' and 'ah'.

The widely used wordless picture book 'Frog where are you?' (Mayer, 1969) was the stimulus for one narrative (FROG) (Strong and Shaver, 1991; Boudreau and Hedberg, 1999; Manhardt and Rescorla, 2002; Norbury and Bishop, 2003). The events depicted have the potential to elicit a narrative that is goal-directed (focused on resolving a problem), more elaborated (as a number of obstacles appear), and contains cohesive chains (as a variety of animal characters appear). The children were allowed to view the entire book and then asked to tell their own story, turning the pictures as they were ready. Children who paused or who said they couldn't tell a story were encouraged to 'look at the picture and tell me what happened here'.

The second oral narrative used a single picture scene as a stimulus, showing two children looking at a cat stuck in a tree (CAT). This stimulus was previously used in a study of narrative development in children aged from 3-7 years (James 1999; 2001). It was hypothesized to be more demanding of processing capacity because it provided less visual support than the FROG book, requiring children to create their own plot (Shapiro and Hudson, 1991). The children were instructed to look at the picture and tell a story about it in the following way: "When you tell your story, you might like to start with "once upon a time". Also, see if you can have a beginning, middle and end to your story'. If children paused without indicating that they had finished the story they were prompted once with 'Tell me more' and a second time with 'Tell me what happened next' (James, 1999).

\section{Coding and analysis}

The oral narratives were audio-recorded, transcribed, and parsed into C-units. Each narrative was then analysed for its structural organization, cohesive devices, and lexical information items. All transcription and analysis was conducted by the first author.

Narrative structure was first analysed using a decision tree and descriptors based on the work of Hedberg and Westby (1993). The narrative levels were then clustered into three broader bands of narrative organization: non-goal-directed, goal-directed, and elaborated, defined in Appendix A. Refusal to tell a narrative was also counted as a level preceding the non-goal directed level, as it indicated that the child found the task too challenging. This resulted in four narrative levels for analysis. The goal-directed and elaborated narratives were 
not at the more mature levels where internal plans are usually evident (e.g. 'the boy decided to/ thought he would look for his frog'). The elaborated narratives had an initial episode with a basic plot structure (initiating event, attempt, and consequence) and subsequent elaboration of obstacles at a reactive sequence or abbreviated episode level. These were considered early forms of elaboration, for the purposes of this research.

Cohesive devices described by Halliday and Hasan (1976) were used as the initial basis for coding cohesion of character identity chains (i.e. successive use of cohesive devices for each story character) within the text: lexical, pronominal reference, demonstrative reference, comparative reference, substitution, and ellipsis. Each cohesive device (or absence of cohesion) was coded for the adequacy of the attempted cohesive tie, similar to the cohesive adequacy classification described by Liles (1985). A description of cohesive devices and their adequacy is presented in Appendix B. All instances of erroneous cohesion were scored for analysis, with adequacy calculated as a percentage of total ties.

A system for scoring information for a retell of the FROG narrative was adapted for this research (Pomper, Rosier, Sauer, Thompson, Weaver, and Hedberg, 1995; Boudreau and Hedberg, 1999). Key lexical items from the story were listed and given a score, including characters, places, objects. and actions. Character names (e.g. Sam) from the story retell criteria were replaced with a lexical label or pronoun (e.g. boy/he) as criteria for the generation context which did not provide pre-determined character names. The revised FROG information scoring criteria contained 130 lexical items, some of which were repeated on each page of the story, shown in Appendix C. A similar information scoring system was created for the CAT narrative, based on likely attempts and resolutions inferred from the pictured problem with up to 127 items, and is shown in Appendix D. The information score for each participant was divided by the maximum information score achieved by the AM participants for the narrative ( 85 for FROG and 18 for CAT) and then converted to a percentage to provide comparable scores for the two narratives.

\section{Reliability}

Inter-rater reliability for point-to-point coding of the narratives was examined by an independent speech pathologist experienced in narrative analysis for $10 \%$ of all narrative samples. Agreement was: $97.2 \%$ for C-unit division, $100 \%$ for narrative organizational level, $86.8 \%$ for the type and adequacy of each instance of character cohesion, and $96 \%$ for the information scores. Problematic coding included differing views on the adequacy of exophoric reference due to the book being in front of the child and the appropriateness of alternative lexical forms (e.g. 'took off with' vs 'carried'). Differences were resolved by consensus.

\section{Statistical analysis}

All data was entered into a statistical software package (Statistical Package for the Social Sciences [SPSS], 2002). Non-parametric methods were used since ordinal measures were required for narrative organization and data was skewed on some measures (Pallant, 2001). The Kruskal-Wallis test was used to determine group differences and the Mann-Whitney test was used for post-hoc pairwise group comparisons. Descriptive statistics are presented as medians and interquartile ranges, consistent with guidelines for reporting non-parametric statistics. A result of statistically significant differences between the AM group and each of the two LI groups (SLI and NLI) was used as an indicator that each measure was a sound identifier of LI and appropriate for further analysis. 
Table IV. Holm adjusted $p$-values for six group comparisons.

\begin{tabular}{lcl}
\hline & Rank & $p$-value \\
\hline Smallest $p$-value & 6 & .008 \\
& 5 & .01 \\
& 4 & .0125 \\
Largest $p$-value & 3 & .017 \\
& 2 & .025 \\
\end{tabular}

The Holm method was used to adjust $p$-values for significance of all post-hoc pairwise comparisons (Aickin and Gensler, 1996). This method reduces the risk of Type 1 errors in multiple comparisons (i.e. determining that differences exist between groups when there are none) and provides less risk of a Type 2 error (i.e. accepting that there are no differences when differences actually exist) than the more stringent Bonferroni method. Briefly, the calculation involves dividing the alpha value (.05) by the rank order of the $p$-values, constrained by the total number of comparisons (six), shown in Table IV.

Effect sizes for each pairwise comparison were calculated using a method recommended for non-parametric statistics (Tabachnick and Fidell, 2007; Field, 2009). The standard variance, measured as a $z$-score, is compared with the square root of the sample size $(r=z /$ $\sqrt{ } n$ ), where $n$ equals the total number of participants in each pairwise comparison. This effect size can be compared to Cohen's estimates for interpretation where $r \geq .50$ is a large effect, $r \geq .30$ is a medium effect, and $r \geq .10$ is a small effect.

\section{Results}

C-units

The number of C-units for each narrative was analysed to provide background information about the length of the narratives (Table V). Overall, the FROG narratives were longer than the CAT narratives for each research group, with the median number of C-units for the FROG narratives ranging from 21-38 across groups. The CAT narratives were quite short, with the median number of C-units ranging from five-to-eight across groups: some children only produced one C-unit for their CAT story. The AM group produced longer narratives than other groups for both stories.

\section{Narrative structural organization}

The percentage of oral narratives produced at each organization level is shown for each group and narrative stimuli in Table VI. The children with SLI and NLI produced less sophisticated

Table V. Number of C-units reported as medians.

\begin{tabular}{lrrrr}
\hline & \multicolumn{3}{c}{ Group } & AM \\
\cline { 2 - 5 } Variable & \multicolumn{1}{c}{ SLI } & NLI & LM \\
\hline FROG no. of c-units & $27(23)$ & $21(14)$ & $38(16)$ & $31(21)$ \\
CAT no. of c-units & $5(4)$ & $7(5)$ & $8(6)$ & $5(4)$ \\
\hline
\end{tabular}

Interquartile ranges are presented in parentheses. 
Table VI. Percentage of narratives at each narrative organization level.

\begin{tabular}{|c|c|c|c|c|c|c|c|c|}
\hline \multirow[b]{3}{*}{ Variable } & \multicolumn{8}{|c|}{ Group } \\
\hline & \multicolumn{2}{|c|}{ SLI } & \multicolumn{2}{|c|}{ NLI } & \multicolumn{2}{|c|}{$\mathrm{AM}$} & \multicolumn{2}{|c|}{$\mathrm{LM}$} \\
\hline & FROG & CAT & FROG & CAT & FROG & CAT & FROG & CAT \\
\hline Refusal & 0 & 0 & 0 & 0 & 0 & 0 & 0 & 15 \\
\hline Non-goal-directed & 60 & 93 & 62 & 85 & 10 & 24 & 100 & 80 \\
\hline Goal-directed & 27 & 7 & 39 & 15 & 38 & 71 & 0 & 5 \\
\hline Elaborated & 13 & 0 & 0 & 0 & 52 & 5 & 0 & 0 \\
\hline
\end{tabular}

Percentiles for median levels are shown in italic font.

narratives than their age-matched peers. However, their FROG narratives were more sophisticated than the younger language-matched group, while their CAT narratives were more similar. The majority of SLI, NLI, and LM participants produced non-goal-directed FROG and CAT narratives, while the majority of the AM group produced elaborated FROG narratives and goal-directed CAT narratives. Several LM participants refused to attempt the CAT narrative. Significant group effects were evident for both the FROG $\left(\chi^{2}(3)=36.522, p<.001\right)$ and CAT narratives $\left(\chi^{2}(3)=32.272, p<.001\right)$.

Post-hoc pairwise comparisons (Table VII) showed that there were no significant differences between the SLI and NLI groups for narrative organization level for either narrative. Both the SLI and NLI groups produced FROG narratives at a significantly higher organizational level than the LM group, with a large effect size (less non-goal-directed, more goal-directed, and more elaborated). However, there were no significant differences among the LM and two LI

Table VII. Significance levels and effect sizes for pairwise comparisons for narrative organization level, cohesive ties, and information scores.

\begin{tabular}{|c|c|c|c|c|c|c|c|}
\hline \multirow[b]{3}{*}{ Measure } & \multirow[b]{3}{*}{ Value } & \multicolumn{6}{|c|}{ Group comparisons } \\
\hline & & \multirow{2}{*}{$\underset{\text { NLI-SLI }}{\text { LI }}$} & \multicolumn{2}{|c|}{ LI \& LM } & \multicolumn{2}{|c|}{$\mathrm{LI} \& \mathrm{AM}$} & \multirow{2}{*}{$\begin{array}{c}\text { TDL } \\
\text { LM-AM }\end{array}$} \\
\hline & & & NLI-LM & SLI-LM & NLI-AM & SLI-AM & \\
\hline \multirow[t]{2}{*}{ FROG organization level } & $p$ & .781 & .005 & .002 & $<.001$ & .001 & $<.001$ \\
\hline & $r$ & & .52 & .52 & .64 & .53 & .86 \\
\hline \multirow[t]{2}{*}{ CAT organization level } & $p$ & .583 & .216 & .305 & .001 & $<.001$ & $<.001$ \\
\hline & $r$ & & & & .58 & .67 & .71 \\
\hline \multirow[t]{2}{*}{ FROG percentage erroneous ties } & $p$ & .114 & .628 & .026 & $<.001$ & $<.001$ & $<.001$ \\
\hline & $r$ & & & & .76 & .70 & .85 \\
\hline \multirow[t]{2}{*}{ FROG information score percentage } & $p$ & .058 & .464 & .005 & $<.001$ & $<.001$ & $<.001$ \\
\hline & $r$ & & & .46 & .77 & .58 & .80 \\
\hline \multirow[t]{2}{*}{ CAT information score percentage } & $p$ & .630 & .528 & .876 & $<.001$ & $<.001$ & $<.001$ \\
\hline & $r$ & & & & .61 & .71 & .65 \\
\hline
\end{tabular}

Effect sizes are presented for significant comparisons as the co-efficient $r$; see Table III for explanation of Holm adjusted significance levels. The group comparisons are clustered, from left to right: $\mathrm{LI}=$ comparison between the SLI and NLI groups; LI \& LM = comparisons between the LM group and each LI group; LI \& AM= comparisons between the AM group and each LI group; TDL = comparison between the AM and LM groups. 
Table VIII. Results for cohesive tie adequacy and information scores, reported as medians.

\begin{tabular}{lccrr}
\hline & \multicolumn{4}{c}{ Group } \\
\cline { 2 - 5 } Variable & SLI & NLI & AM & LM \\
\hline FROG erroneous ties (\%) & $30(33)$ & $46(38)$ & $2(9)$ & $45(38)$ \\
FROG information score (\%) & $37(27)$ & $24(15)$ & $68(28)$ & $22(11)$ \\
CAT information score (\%) & $22(17)$ & $28(19)$ & $56(25)$ & $22(17)$ \\
\hline
\end{tabular}

Interquartile ranges are presented in parentheses.

groups for the CAT narrative. The AM group produced both FROG and CAT narratives at significantly higher organization levels than the other three groups, with large effect sizes.

\section{Character cohesion}

Cohesion results for the CAT narratives were limited in several ways. First, there were no cohesive tie attempts from $17 \%$ of participants across all groups, particularly the LM group, due to insufficient C-units (note that cohesive adequacy is calculated as a percentage of the total number of ties and can not be calculated for zero ties). Secondly, the number of c-units (Table III), and hence cohesive ties, for the CAT narratives across all groups was quite small. Thirdly, statistical analysis revealed no significant differences in cohesive adequacy between the SLI and AM groups for the CAT narrative, suggesting this stimulus was not effective at identifying cohesive deficits in LI. Therefore, further statistical analysis of cohesive adequacy for the CAT narrative was not considered useful.

For the FROG narrative, descriptive statistics (Table VIII) show high use of erroneous ties among the SLI, NLI, and LM groups, with very few for the AM group. Group effects for erroneous ties were significant $\left(\chi^{2}(3)=40.052, p=.001\right)$. Post-hoc pairwise comparisons (Table V) showed that there were no significant differences among the SLI, NLI, and LM groups. The AM group produced significantly fewer erroneous ties than the other three groups, with large effect sizes.

\section{Information scores}

The AM group provided the greatest amount of information for both narratives while the LM group provided the least, shown in Table VIII. Group effects were significant for both the FROG $\left(\chi^{2}(3)=37.406, p=.001\right)$ and CAT narratives $\left(\chi^{2}(3)=26.976, p=.001\right)$.

Post-hoc pairwise comparisons (Table VII) showed that there were no significant differences between the SLI and NLI groups for either the FROG or CAT narratives. The SLI group attained significantly higher information percentage scores than the LM group for the FROG narrative, with a moderate effect size. For both the FROG and CAT narratives, the AM group attained a significantly higher information score than the other three groups, with large effect sizes.

\section{Discussion}

In relation to the first research question, the SLI and NLI groups performed similarly for narrative organization, cohesion, and information provision. In relation to the second research question, significant effects were evident for LI (the AM group performed better than the two LI groups) 
and for age across the two TDL groups (the AM group performed better than the LM group). These latter findings show that the measures used were effective for identifying LI and developmental differences. Also in relation to the second research question, significant differences were evident between the SLI and younger LM groups for some measures for the FROG narrative, with the SLI participants performing better on measures of organization and information.

\section{Implications of SLI and NLI comparisons}

The findings of this study concur with those of Fey et al. (2004), who found no significant differences between children with SLI and NLI for grammatical accuracy or narrative plot, context, and quality. However, the findings are not fully consistent with the view that oral narrative is as much a cognitive as a linguistic task (Liles, 1993). The SLI and NLI groups were matched for language skills on the basis of MLU from a conversational sample and on their CELF-P scores which assessed vocabulary, grammatical skills, and verbal memory. However, they differed significantly in their non-verbal cognitive abilities, the major diagnostic distinction between these two groups. If the oral narrative skills assessed relied heavily on non-verbal cognitive skills, then a difference between SLI and NLI would have been the expected outcome.

The similar narrative skills of children with SLI and NLI suggest that linguistic skills contributed more to structural organization, cohesion, and information provision than did non-verbal cognitive skills. Grammatical and vocabulary skills form critical building blocks for narrative cohesion and information provision. However, the link between these linguistic skills and oral narrative structural organization is more complex. Narrative organization requires the ability to organize ideas, causal relations, and event sequences as well the ability to linguistically encode these using appropriate grammatical forms and vocabulary. Nonetheless, these findings support the notion that linguistic skills underlie or support narrative organization, as also argued by others (Hemphill et al., 1991; Strong and Shaver, 1991; Liles, 1993; Liles et al., 1995; Norbury and Bishop, 2003).

\section{Implications of LI and LM comparisons}

This study is distinctive in comparing the oral narrative skills of children with both SLI and NLI to a younger TDL group with similar levels of linguistic skill (LM). Although the SLI, NLI, and LM groups were matched for MLU and grammatical accuracy, this linguistic equivalence did not result in similar levels of oral narrative production across all three groups for all measures. Similar levels of cohesive adequacy across the SLI, NLI, and LM groups suggest that these skills are primarily a product of their similar linguistic abilities. In contrast, significantly better narrative organization in the LI groups, compared to the LM group, suggest that other factors were at play. This contrasts with a previous finding that children with SLI produced less complex oral narratives than a younger language-matched group, but this may reflect the different ages studied (Olley, 1989; Gillam and Carlile, 1997).

While both the SLI and LM groups had appropriate non-verbal cognitive development, their cognitive skills were not at the same level due to their age differences. The NLI and LM groups were more similar, matched for raw scores on the RCPM. However, both the SLI and NLI groups had greater benefits of maturation, age, and life experience than the LM group. The children with SLI and NLI were all attending a pre-school or school where they were exposed to stories and literate learning activities (Department of Education and Children's Services [DECS], 2001). They would have experienced varying levels of exposure to stories within their families for more years than the younger LM group (Peterson and McCabe, 1994). This higher 
level of experience most likely contributed to the ability of the children with SLI and NLI to produce stories that were structurally more complex than the younger LM group. The older children with SLI and NLI possessed story schemas and had more knowledge about how to tell a story, while the younger LM group were using their language skills for a different purpose (to interact through the story or to coax the adult to tell the story).

For the FROG narrative, the SLI and NLI groups produced a number of goal-directed narratives (20-40\%), while the younger LM group only produced non-goal-directed narratives. By implication, the children with SLI and NLI in this study were better able to use the picture sequences in the FROG story to construct a story plot due to their greater experience and maturation, than were the LM group. Since the SLI group differed from the NLI and LM groups on their scores for the RCPM, cognitive skills alone could not account for this difference. The older children with SLI and NLI seemed to benefit from their greater years of experience with life events, pre-school education, and story books. This finding was not evident for the CAT narrative, with similarity in the structural organization of these narratives among the SLI, NLI, and LM groups.

The SLI group produced FROG narratives that were significantly more informative, than the younger LM group. The FROG narrative stimulus provided pictures that the SLI group was better able to use as prompts for the scored lexical items. The NLI group were not statistically differentiated from either the SLI or LM groups, suggesting that their skills with information provision lay somewhat between the two. More mature cognitive skills may be implicated here as providing the advantage for the SLI group in using the picture stimulus. This effect was not apparent for the CAT narrative, suggesting that the SLI, NLI, and LM groups found it equally difficult to create and encode ideas for a story about this single scene picture into lexical forms to describe characters and events.

This complex pattern of differences and similarities points to interactive contributions from cognitive development and experience; however, the contribution from linguistic skills was clearly greater than the contribution from non-verbal cognitive skills. Only a trend for a contribution from non-verbal cognitive skills to oral narrative production was evident.

\section{Task appropriateness}

The FROG story was previously used for a comparison of SLI and age-matched TDL in children of similar age by Boudreau and Hedberg (1999), but in a retell task. Findings for narrative organization differed for those in the current study, possibly due to retell vs generation effects, or to differences in the way that narrative organization was scored. Boudreau and Hedberg scored key plot events in their narratives with no significant differences apparent between SLI and TDL. In contrast, the current study found that a scoring system using broad organization levels was effective at differentiating SLI and TDL as well as differentiating NLI from an age-matched TDL group (AM). Generation tasks are considered more challenging than retell tasks so the additional challenge of generating a story may have been the key variable that differentiated the children with SLI and NLI from the AM group in this study (Hughes et al., 1997). This current study had some similar findings to Boudreau and Hedberg, as the children with SLI attained significantly poorer information scores than children with TDL (AM group). This suggests that the information scoring system is sensitive to $\mathrm{LI}$ in both retell and generation tasks.

The high number of refusals for the CAT narrative from the young LM group suggests that this narrative stimulus was much too difficult for them (also evident in James, 2001). Younger children are not used to independent story-telling, as was expected with the single scene picture (Ukrainetz, 2006). While there were no significant differences between the LI and LM 
groups for narrative organization or information for the CAT narrative, the older children with SLI and NLI did not refuse to attempt a story. This suggests that their age and experience lead to greater independence and confidence in approaching narrative tasks, with less reliance on co-construction and prompting support. In contrast, the changing pages of the FROG wordless picture book may have provided sufficient prompts to maintain some level of motivation for the young children to provide comments on each page.

The LM group often labelled pictures and described pictured events for both narrative tasks, but did not link these into a goal-directed story. The younger children ( 2 and 3-year olds) often showed a preference for dialogue about the story and asking questions (e.g. 'what's that?', 'you tell me'). While this type of dialogue was not subject to further analysis, it is consistent with the finding that younger children rely on prompts, and that conversationally prompted personal event narratives are a more appropriate and successful genre for young children than fictional narratives (Peterson, 1993; Allen, Kertoy, Sherblom, and Pettit, 1994; McCabe and Rollins, 1994). The 5-year old children were much more independent in their approach, with the AM group capable of producing goal-directed oral narratives in response to picture stimuli.

\section{Limitations and implications for future research}

Participant numbers for this study were small and from a limited age range so it is uncertain whether the same findings will hold for the broader population of children with LI. Larger sample sizes across a wider age range would provide further information about the usefulness of comparisons between children with LI and a younger language-matched group with TDL (the LM group) for exploring oral narrative differences. Greater participant numbers would also facilitate application of research methods that explore the relationships among variables such as non-verbal cognition, MLU, age, and oral narrative skills (e.g. correlation or regression analysis) (Tabachnick and Fidell, 2007).

Use of the RCPM for measuring non-verbal ability and grouping participants provided a limited analysis of group characteristics. While raw scores enabled broad differentiation into groups it was not possible to ascertain a percentile rank for all participants. Further research is also needed to explore the impact of different cut-off scores for language and non-verbal cognitive abilities on oral narrative differences and similarities among SLI, NLI, and LM groups. Different assessment tools and criteria are known to result in diagnostic variations (Aram, Morris, and Hall, 1993). The use of different assessments may have led to different findings for the participants in this study.

Measures of variance (interquartile ranges) in this study were quite high, even for the AM group. This is consistent with the finding that oral narrative abilities differ widely among young children with TDL (Berman and Slobin, 1994; McCabe and Rollins, 1994; Johnson, 1995). Clear differences in oral narrative skills between LI diagnostic groups may be obscured by the variable nature of oral narrative skills in young children.

\section{Implications for clinical practice}

The absence of differences between SLI and NLI questions the value of considering them as discrete diagnostic categories in clinical contexts (also see Ellis Weismer et al., 2000). Language assessment, analysis, and diagnostic processes remain similar for each group and will most likely lead to similar profiles of oral narrative intervention targets. Clear effects for LI across both diagnostic groups reinforce that assessment of oral narrative skills is an important and useful part of the assessment process for all children with LI. On the other hand, a categorical approach to 
non-verbal cognitive assessments, with an emphasis on differentiating SLI from NLI, is unlikely to predict the nature of linguistic impairments or the ability to structure an oral narrative.

Narrative stimuli need to be carefully selected for maximum effect. The FROG wordless picture book yielded more useful results for cohesion and revealed differences between the LI and LM groups on narrative organization and information measures that were not evident for the CAT single scene picture. This concurs with previous research comparing the FROG and CAT stimuli in children with TDL (Pearce, 2003) in young children. Further exploration of the impact of various oral narrative stimuli on differential diagnosis is needed.

While the absence of diagnostic distinctions between SLI and NLI indicates similar needs for language intervention, exploration of comparative intervention effects on oral narrative for children with SLI and NLI is not evident in the literature. Children with SLI may have other skills that give them an advantage with intervention tasks and language learning strategies. A dynamic assessment approach may be one way to explore whether cognitive learning strategies differ between children with SLI and NLI and produce different outcomes for oral narrative acquisition (Gutiérrez-Clellan and Peña, 2001; Miller, Gillam, and Peña, 2001; Hasson and Joffe, 2007). In the meantime, best practice principles encourage clinicians to explore the unique profiles of individual clients and to target intervention to their specific needs (Dale and Cole, 1991; Bernstein Ratner, 2006; Paul, 2007).

\section{Conclusion}

Clinicians need to be wary of over-interpreting the significance of non-verbal cognitive differences among children with LI, particularly between SLI and NLI. There is no conclusive evidence that these differences contribute significantly to linguistic skills or to the ability to organize an oral narrative. There is some evidence that children with NLI may have more severe oral narrative deficits than children with SLI, also suggested by Fey et al. (2004). This is seen in the trend for the NLI group to be similar to the LM group, more so than the SLI group. However, these trends were not large enough to reveal significant differences between the oral narratives of the 5-year-old SLI and NLI participants in this study.

\section{Acknowledgements}

This paper is based on the first author's work towards a $\mathrm{PhD}$ at Flinders University, supervized by the remaining authors. We are thankful to the speech pathologists, teachers, and parents who referred and supported their children's involvement. We are particularly grateful to Sue Horton, Melissa Saliba, and Sue McCandlish who assisted with the reliability checks. Ethics approval for this project was granted by the Flinders Clinical research Ethics Committee (approval number 60/02) and the Research Council Unit of the South Australian Department of Education, Training Employment. Approval was also provided by the director/principal of each preschool/school site to proceed with the research project before seeing participants.

Declaration of interest: The authors report no conflicts of interest. The authors alone are responsible for the content and writing of the article.

\section{References}

Aickin, M., \& Gensler, H. (1996). Adjusting for multiple testing when reporting research results: the Bonferroni vs Holm methods. American Fournal of Public Health, 86, 726-728. 
Allen, M. S., Kertoy, M. K., Sherblom, J. C., \& Pettit, J. M. (1994). Children's narrative productions: a comparison of personal event and fictional stories. Applied Psycholinguistics, 15, 149-176.

Aram, D. M., Morris, R., \& Hall, N. E. (1993). Clinical and research congruence in identifying children with specific language impairment. Fournal of Speech and Hearing Research, 36, 580-591.

Berman, R. A., \& Slobin, D. I. (1994). Relating events in narrative: A crosslinguistic developmental study. Hillsdale, NJ: Lawrence Erlbaum Associates.

Bernstein Ratner, N. (2006). Evidence-based practice: an examination of its ramifications for the practice of speechlanguage pathology. Language, Speech and Hearing Services in Schools, 37, 257-267.

Bishop, D.M. V. (1994). Grammatical errors in specific language impairment: competence or performance limitations? Applied Psycholinguistics, 15, 507-550.

Boudreau, D. M., \& Hedberg, N. L. (1999). A comparison of early literacy skills in children with specific language impairment and their typically developing peers. American fournal of Speech-Language Pathology, 8, 249-260.

Casby, M. W. (1992). The cognitive hypothesis and its influence on speech-language services in schools. Language, Speech, and Hearing Services in Schools, 23, 198-202.

Copmann, K.S. P., \& Griffith, P. L. (1994). Event and story structure recall by children with specific learning disabilities, language impairments, and normally achieving children. Fournal of Psycholinguistic Research, 23, 231-247.

Dale, P. S., \& Cole, K. N. (1991). What's normal? Specific language impairment in an individual differences perspective. Language, Speech, and Hearing Services in Schools, 22, 80-83.

Department of Education and Children's Services (DECS). (1996). Caseload management strategies: Guidelines for frequency of intervention. Adelaide, South Australia: Department for Education and Children's Services.

Department of Education and Children's Services (DECS). (2001). South Australian curriculum standards and accountability framework. Retrieved 31 August 2008, from http://www.sacsa.sa.edu.au/index_fsrc.asp?t=Home, accessed.

Dockrell, J. E., Lindsay, G., Letchford, B., \& Mackie, C. (2006). Educational provision for children with specific speech and language difficulties: perspectives of speech and language therapy service managers. International Fournal of Language and Communication Disorders, 41, 423-440.

Eaton, J. H., Collis, G. M., \& Lewis, V. A. (1999). Evaluative explanations in children's narratives of a video sequence without dialogue. Fournal of Child Language, 26, 699-720.

Eckler, J. A., \& Weininger, O. (1989). Structural parallels between pretend play and narratives. Developmental Psychology, 25, 736-743.

Education Queensland (2003). Guidelines for speech-language impairment. Retrieved 14 February 2009, from http:/education.qld.gov.au/curriculum/learning/students/disabilities/policy/slpguidelines.pdf.

Edwards, S., Fletcher, P., Garman, M., Hughes, A., Letts, C., \& Sinka, I. (1997). Reynell developmental language scales III (University of Reading, 3rd ed.) Windsor: NFER-Nelson.

Elliott, C. D. (1990). Differential ability scales. San Antonio: Psychological Corporation.

Ellis Weismer, S., Tomblin, J. B., Zhang, X., Buckwalter, P., Chynoweth, J. G., \& Jones, M. (2000). Nonword repetition performance in school-age children with and without language impairment. Fournal of Speech, Language, and Hearing Research, 43, 865-878.

Fey, M. E., Catts, H. W., Proctor-Williams, K., Tomblin, J. B., \& Zhang, X. (2004). Oral and written story composition skills of children with language impairment. Fournal of Speech, Language, and Hearing Research, 47, 1301-1318.

Field, A. (2009). Discovering statistics using SPSS. 3rd ed. London: SAGE.

Gillam, R. B., \& Carlile, R. M. (1997). Oral reading and story retelling of students with specific language impairment. Language, Speech, and Hearing Services in Schools, 28, 30-42.

Gutiérrez-Clellan, V. F., \& Peña, E. (2001). Dynamic assessment of diverse children: a tutorial. Language, Speech and Hearing Services in Schools, 32, 212-224.

Halliday, M.A. K., \& Hasan, R. (1976). Cohesion in English. London: Longman.

Hasson, N., \& Joffe, V. (2007). The case for dynamic assessment in speech and language therapy. Child Language Teaching and Therapy, 23, 9-25.

Haynes, W. O., \& Pindzola, R. H. (2008). Diagnosis and evaluation in speech pathology. 7th ed. Boston, MA: Pearson Education.

Hedberg, N. L., \& Westby, C. E. (1993). Analyzing storytelling skills: Theory to practice. Tucson: Communication Skill Builders.

Hemphill, L., Picardi, N., \& Tager-Flusberg, H. (1991). Narrative as an index of communicative competence in mildly mentally retarded children. Applied Psycholinguistics, 12, 263-279.

Hughes, D., McGillivray, L., \& Schmidek, M. (1997). Guide to narrative language: Procedures for assessment. Eau Claire, WI: Thinking Publications. 
James, D. (1999). Children's story telling skills in the age range of five to seven years. In S. McLeod, \& L. McAllister (Eds.), Towards 2000: Embracing change, challenge and choice: Proceedings of the 1999 Speech Pathology Australia National Conference (pp. 102-109). Melbourne: Speech Pathology Australia.

James, D.G. H. (2001). Story telling skills in children aged 3;0 to 5;11 years. In L. Wilson \& S. Hewat (Eds.), Evidence and Innovation: Proceedings of the 2001 Speech Pathology Australia National Conference (pp. 171-179). Melbourne: Speech Pathology Australia.

Johnson, C. J. (1995). Expanding norms for narration. Language, Speech, and Hearing Services in Schools, 26, $326-341$.

Kaderavek, J. N., \& Sulzby, E. (2000). Narrative production by children with and without specific language impairment: oral narratives and emergent readings. Fournal of Speech, Language, and Hearing Research, 43, 34-49.

Leonard, L. B. (1998). Children with specific language impairment. Cambridge: The MIT Press.

Leonard, L. B., Eyer, J. A., Bedore, L. M., \& Grela, B. G. (1997). Three accounts of the grammatical morpheme difficulties of English-speaking children with specific language impairment. Fournal of Speech, Language, and Hearing Research, 40, 741-753.

Liles, B. Z. (1985). Cohesion in the narratives of normal and language-disordered children. Fournal of Speech and Hearing Research, 28, 123-133.

Liles, B. Z. (1987). Episode organization and cohesive conjunctives in narratives of children with and without language disorder. Fournal of Speech and Hearing Research, 30, 185-196.

Liles, B. Z. (1993). Narrative discourse in children with language disorders and children with normal language: a critical review of the literature. Fournal of Speech and Hearing Research, 36, 868-882.

Liles, B. Z., Duffy, R. J., Merritt, D. D., \& Purcell, S. L. (1995). Measurement of narrative discourse ability in children with language disorders. Fournal of Speech and Hearing Research, 38, 415-425.

Manhardt, J., \& Rescorla, L. (2002). Oral narrative skills of late talkers at ages 8 and 9. Applied Psycholinguistics, 23, 1-21.

Mayer, M. (1969). Frog, where are you? New York: Pied Piper.

McCabe, A., \& Rollins, P. R. (1994). Assessment of preschool narrative skills. American fournal of Speech-Language Pathology, 3, 45-55.

Merritt, D. D., \& Liles, B. Z. (1987). Story grammar ability in children with and without language disorder: story generation, story retelling, and story comprehension. Fournal of Speech and Hearing Research, 30, 539-552.

Miller, L., Gillam, T. B., \& Peña, E. D. (2001). Dynamic assessment and intervention: Improving children's narrative abilities. Austin, TX: Pro-Ed.

Miranda, A. E., McCabe, A., \& Bliss, L. S. (1998). Jumping around and leaving things out: a profile of the narrative abilities of children with specific language impairment. Applied Psycholinguistics, 19, 647-667.

Norbury, C. F., \& Bishop, D.V. M. (2003). Narrative skills of children with communication impairments. International fournal of Language and Communication Disorders, 38, 287-313.

Olley, L. (1989). Oral narrative performance of normal and language impaired school aged children. Australian Fournal of Human Communication Disorders, 17, 43-65.

Pallant, J. (2001). SPSS survival manual. Crows Nest, NSW: Allen \& Unwin.

Paul, R. (2007). Language disorders from infancy through adolescence: Assessment and intervention. 3rd ed. St Louis, MI: Mosby Inc.

Paul, R., Hernandez, R., Taylor, L., \& Johnson, K. (1996). Narrative development in late talkers: early school age. Fournal of Speech and Hearing Research, 39, 1295-1303.

Paul, R., \& Smith, R. L. (1993). Narrative skills in 4-year-olds with normal, impaired, and late-developing language. Fournal of Speech and Hearing Research, 36, 592-598.

Pearce, W. M. (2003). Does the choice of stimulus affect the complexity of children's oral narratives? Advances in Speech Language Pathology, 5, 95-103.

Pearce,W. M. (2006). The role of morphosyntax and oral narrative in the differential diagnosis of specific language impairment. Doctoral thesis, Flinders University, Adelaide, South Australia. Retrieved 6 December 2008, from http://www.lib.flinders.edu.au/theses/.

Pearce, W. M., McCormack, P. F., \& James, D.G. H. (2003). Exploring the boundaries of SLI: findings from morphosyntactic and story grammar analyses. Clinical Linguistics and Phonetics, 17, 325-334.

Peterson, C. (1993). Identifying referents and linking sentences cohesively in narration. Discourse Processes, 16, 507-524.

Peterson, C., \& McCabe, A. (1994). A social interactionist account of developing decontextualized narrative skill. Developmental Psychology, 30, 937-948.

Pomper, C. A., Rosier, E., Sauer, J. A., Thompson, A., Weaver, S., \& Hedberg, N. L. (1995). Preschool children's story retelling: Comparison of English, Hmong and Spanish. Unpublished manuscript, University of Colarado, Boulder.

Raven, J. C., Court, J. H., \& Raven, J. (1995). Coloured progressive matrices. Oxford: Oxford Psychologists Press. 
Rice, M. L., Tomblin, J. B., Hoffman, L., Richman, W. A., \& Marquis, J. (2004). Grammatical tense deficits in children with SLI and nonspecific language impairment: relationships with nonverbal IQ over time. Fournal of Speech, Language, and Hearing Research, 47, 816-834.

Rice, M. L., Wexler, K., Marquis, J., \& Hershberger, S. (2000). Acquisition of irregular past tense by children with specific language impairment. Fournal of Speech, Language, and Hearing Research, 43, 1126-1145.

Shapiro, L. R., \& Hudson, J. A. (1991). Tell me a make-believe story: coherence and cohesion in young children's picture-elicited narratives. Developmental Psychology, 27, 960-974.

Spinillo, A. G., \& Pinto, G. (1994). Children's narratives under different conditions: a comparative study. British Fournal of Developmental Psychology, 12, 177-193.

Statistical Package for the Social Sciences (SPSS). (2002). SPSS for Windows. Version 11.5.0. Chicago: SPSS Inc.

Stothard, S. E., Snowling, M. J., Bishop, D.V. M., Chipchase, B. B., \& Kaplan, C. A. (1998). Language-impaired preschoolers: a follow-up into adolescence. Fournal of Speech, Language, and Hearing Research, 41, 407-418.

Strong, C. J., \& Shaver, J. P. (1991). Stability of cohesion in the spoken narratives of language-impaired and normally developing school-aged children. Fournal of Speech and Hearing Research, 34, 95-111.

Tabachnick, B. G., \& Fidell, L. S. (2007). Using multivariate statistics. 5th ed. Sydney: Pearson Education.

Tomblin, J. B., \& Zhang, X. (1999). Language patterns and etiology in children with specific language impairment. In H. Tager-Flusberg (Ed.), Neurodevelopmental disorders: Developmental cognitive neuroscience (pp. 361-382). Cambridge, MA: MIT Press.

Ukrainetz, T. A. (2006). Teaching narrative structure: coherence, cohesion and captivation. In T. A. Ukrainetz (Ed.), Contextualised language intervention: Scaffolding PreK-12 literacy achievement (pp. 195-246). Greenville, SC: Thinking Publications.

van der Lely, H.K. J. (1997). Narrative discourse in grammatical specific language impaired children: a modular language deficit? Fournal of Child Language, 24, 221-256.

van Dijk, T. A., \& Kintsch, W. (1983). Strategies of discourse comprehension. New York: Academic Press.

Wagner, C. R., Sahlen, B., \& Nettelbladt, U. (1999). What's the story? Narration and comprehension in Swedish preschool children with language impairment. Child Language Teaching and Therapy, 15, 113-137.

Watkins, R. V. (1994). Specific language impairments in children: an introduction. In R. V. Watkins, \& M. L. Rice (Eds.), Specific language impairments in children (pp. 1-15). Baltimore: Paul H. Brookes.

Wechsler, D. (1989). Weschler preschool and primary scale of intelligence — revised. San Antonio: Psychological Corporation.

Wechsler, D. (1992). Wechsler intelligence scale for children III (Australian Adaptation ed.). New York: Psychological Corporation.

Wellhousen, K. (1993). Eliciting and examining young children's storytelling. fournal of Research in Childhood Education, 7, 62-66.

Westby, C. E. (1991). Learning to talk-talking to learn: oral-literate language differences. In C. S. Simon (Ed.), Communication skills and classroom success: Assessment and therapy methodologies for language and learning disabled students (pp. 181-213). San Diego: College-Hill.

Wiig, E., Secord, W., \& Semel, E. (1993). Clinical evaluation of language fundamentals-preschool. San Antonio: Harcourt Brace \& Company.

\section{Appendix A: Definition of narrative organizational levels}

\begin{tabular}{|c|c|}
\hline Organizational level & Definition \\
\hline Refusal & Child refuses to attempt to tell a story. \\
\hline $\begin{array}{l}\text { Non-goal-directed } \\
\text { (NGD) }\end{array}$ & $\begin{array}{l}\text { A loosely formed description of characters, things, actions, or events that are not goal- } \\
\text { directed }\end{array}$ \\
\hline Goal-directed (GD) & $\begin{array}{l}\text { Central characters are engaged in intentional behaviour, focused on resolution of a problem } \\
\text { with an identifiable plot structure (initiating event, attempts, and consequence). }\end{array}$ \\
\hline Elaborated & $\begin{array}{l}\text { Two or more episodes. The primary episode is goal-directed with additional episodes } \\
\text { showing causal event relationships (at least an initiating event and a consequence) or goal- } \\
\text { directed behaviour related to resolution of the identified problem. }\end{array}$ \\
\hline
\end{tabular}


Appendix B: Definition of cohesive tie adequacy for each type of cohesive device

Pronominal reference

Demonstratives and definite article; Comparative reference Substitution

Ellipsis
Use of a pronoun that refers to a lexical identification made earlier in the text (e.g. he, they)

Use of demonstrative or definite article with lexical item (e.g. the boy)

Use of a comparator (e.g. the other frog)

Use of a less specific form that refers to a lexical identification made earlier in the text

(e.g. picked one up)

Omission of character identity that is clear from the previous clause (e.g. Where are you? $\varnothing$ over here.)
Exophoric

Erroneous

$\mathrm{n} / \mathrm{a}$

Character is incorrectly named or identified (e.g. calling a reindeer a horse).

Character identified is not depicted and is unclear, too general, ambiguous, or illogical for the textual context.

Use of a pronoun reference Use of pronoun whose identity for an identity that is implicit from the picture context and proposition $\mathrm{n} / \mathrm{a}$ is unclear or ambiguous (e.g. he lost his frog and he is barking).

Use of indefinite article with a repeated lexical item; omission of article or demonstrative

(e.g. a boy is looking and a boy is shouting).

Use of a less specific form for an identity that is implicit from the picture context and proposition Omission of character identity that is implicit from the picture context and proposition
Use of substitution where the identity is unclear or ambiguous (e.g. one going up).

The c-unit omits any identification of a character who is agent of the proposition, resulting in ambiguity (e.g. $\varnothing$ go in and fall off again).

Note: Adapted from Halliday and Hasan (1976) and Liles (1985); Ø denotes an omitted item.

\section{Appendix C. Information score guidelines for FROG narrative}

\begin{tabular}{|c|c|c|c|c|c|}
\hline Page & Item & Score & Page & Item & Score \\
\hline \multirow[t]{7}{*}{1.} & night & & 8. & boy/he \} they & \\
\hline & boy & & & $\operatorname{dog}\}$ & \\
\hline & $\operatorname{dog}$ & & & went/walk & \\
\hline & bedroom & & & forest/wood/outside & \\
\hline & frog & & & look for/search & \\
\hline & in a jar & & & frog & \\
\hline & Sub total & 16 & & call/said/shout & \\
\hline \multirow[t]{7}{*}{2.} & boy/he $\}$ they & & & 'where are you?' & \\
\hline & $\operatorname{dog}\}$ & & & Sub total & $/ 8$ \\
\hline & sleep/asleep/in bed & & 9. & boy/he & \\
\hline & frog & & & look & \\
\hline & climb/hop/got & & & hole & \\
\hline & out & & & ground & \\
\hline & Sub total & 16 & & Sub total & $/ 4$ \\
\hline 3. & morning & & 10. & gopher $\left(^{\star}\right)$ & \\
\hline & boy/he $\}$ they & & & jump/came out & \\
\hline & $\operatorname{dog}\}$ & & & scare & \\
\hline & woke up & & & $\operatorname{dog}$ & \\
\hline
\end{tabular}




\begin{tabular}{|c|c|c|c|c|c|}
\hline Page & Item & Score & Page & Item & Score \\
\hline & frog & & & bark & \\
\hline & gone/not see/not there & & & beehive/bees & \\
\hline & Sub total & 16 & & tree & \\
\hline \multirow[t]{7}{*}{4.} & boy/he $\}$ they & & & shook/jump & \\
\hline & $\operatorname{dog}\}$ & & & Sub total & 18 \\
\hline & look & & 11. & beehive & \\
\hline & frog & & & fell/down & \\
\hline & boot & & & ground & \\
\hline & jar/container & & & bees & \\
\hline & Sub total & 16 & & flew out & \\
\hline \multirow[t]{7}{*}{5.} & boy/he $\}$ they & & & & \\
\hline & $\operatorname{dog}\}$ & & & boy/dog & \\
\hline & look out & & & look & \\
\hline & window & & & tree & \\
\hline & call/said/shout & & & hole & \\
\hline & 'where are you?' & & & Sub total & $/ 9$ \\
\hline & Sub total & 16 & 12. & owl $(\star)$ & \\
\hline \multirow[t]{4}{*}{6.} & $\operatorname{dog}$ & & & jump/came out & \\
\hline & fell out/jumped & & & scare/chase & \\
\hline & jar on (his) head & & & boy/he & \\
\hline & Sub total & 13 & & fell & \\
\hline \multirow[t]{6}{*}{7.} & jar smashed/broke & & & & \\
\hline & boy/he & & & $\operatorname{dog}$ & \\
\hline & pick up/hold/cuddle & & & $\operatorname{ran}$ & \\
\hline & $\operatorname{dog}$ & & & bees & \\
\hline & cross/ naughty & & & chase & \\
\hline & Sub total & 15 & & Sub total & $/ 9$ \\
\hline \multirow[t]{6}{*}{13.} & owl & & 20. & boy/he & \\
\hline & flew (away)/chase & & & said & \\
\hline & boy & & & 'shh'/quiet & \\
\hline & hiding/bottom & & & Sub total & 13 \\
\hline & rock & & 21. & boy/he \} they & \\
\hline & Sub total & 15 & & $\operatorname{dog}\}$ & \\
\hline \multirow[t]{6}{*}{14.} & boy/he & & & look/climb & \\
\hline & climb & & & over/behind & \\
\hline & rock & & & $\log /$ wood & \\
\hline & call/said/shout & & & Sub total & $/ 5$ \\
\hline & 'where are you'? & & 22. & boy/he \} they & \\
\hline & Sub total & 15 & & $\operatorname{dog}\}$ & \\
\hline \multirow[t]{5}{*}{15.} & boy/he & & & saw/found & \\
\hline & caught/hang & & & $\operatorname{frog}(\mathrm{s})$ & \\
\hline & $\operatorname{deer}\left(^{\star}\right)$ & & & Sub total & $/ 4$ \\
\hline & antlers & & 23. & happy & \\
\hline & Sub total & $/ 4$ & & $\mathrm{mum} / \mathrm{dad} / \mathrm{big}$ & \\
\hline \multirow[t]{6}{*}{16.} & deer & & & little/baby/family & \\
\hline & carried/ran (away) & & & $\operatorname{frog}(s)$ & \\
\hline & boy/him & & & Sub total & $/ 4$ \\
\hline & $\operatorname{dog}$ & & 24. & boy/he & \\
\hline & ran & & & took/got/carry/pickup & \\
\hline & Sub total & $/ 5$ & & frog & \\
\hline \multirow[t]{3}{*}{17.} & deer/moose & & & home & \\
\hline & threw/drop/push & & & 'bye' & \\
\hline & boy/him $\}$ them & & & Sub total & 15 \\
\hline
\end{tabular}




\begin{tabular}{|c|c|c|c|c|c|}
\hline Page & Item & Score & Page & Item & Score \\
\hline & $\operatorname{dog}\}$ & & & & \\
\hline & fell/off/down & & & & \\
\hline & cliff/hill & & & TOTAL & $/ 130$ \\
\hline & Sub total & 16 & & & \\
\hline \multirow[t]{5}{*}{18} & boy/he \} they & & & & \\
\hline & $\operatorname{dog}\}$ & & & & \\
\hline & fell/into/landed & & & & \\
\hline & pond/water & & & & \\
\hline & Sub total & $/ 4$ & & & \\
\hline \multirow[t]{4}{*}{19.} & $\operatorname{dog}$ & & & & \\
\hline & on boy's/his head & & & & \\
\hline & $\begin{array}{l}\text { listen/heard } \\
\text { sound of frog }\end{array}$ & & & & \\
\hline & Sub total & $/ 4$ & & & \\
\hline
\end{tabular}

Note: Cohesive pronominal reference to dog, frog, and others gain an information score. Inclusion of dog with boy as 'they' gains an information score. Adapted from Pomper et al. (1995).

\section{Appendix D. Information scoring guidelines for CAT narrative}

\begin{tabular}{|c|c|c|}
\hline Category & Item & Score \\
\hline Character & $\begin{array}{l}\text { Cat; boy/man; girl/lady; children/people (2); mum; dad; other person(s) } \\
\text { (e.g. fireman, neighbour); names; relationships (e.g. brother, friends, twins) } \\
\text { Max. sub total }\end{array}$ & $\begin{array}{l}1 \text { point } \\
\text { each item } \\
\quad / 10\end{array}$ \\
\hline \multirow[t]{2}{*}{ Object } & Tree; branch; drink/milk; bottle; bowl; food; hand & $\begin{array}{l}1 \text { point } \\
\text { each item }\end{array}$ \\
\hline & Max. Sub total & $/ 7$ \\
\hline Place & $\begin{array}{l}\text { in/to the yard park/forest or other appropriate place; into the girl's/boy's hand/ } \\
\operatorname{arm}(\mathrm{s}) \text {; went home/inside } \\
\text { Max. Sub total }\end{array}$ & $\begin{array}{l}1 \text { point } \\
\text { each item } \\
1 / 3\end{array}$ \\
\hline \multirow[t]{2}{*}{ Time } & once upon a time; one day/morning/afternoon; after/before (relevant event) & $\begin{array}{l}1 \text { point } \\
\text { each item }\end{array}$ \\
\hline & Max. Sub total & 13 \\
\hline \multirow[t]{2}{*}{ Description } & $\begin{array}{l}\text { description of tree (e.g. didn't have many leaves; old); height of tree/branch or } \\
\text { difficulty of tree for climbing; description of branch (e.g. big brown branch); } \\
\text { description of cat (e.g. little grey cat); description of girl (e.g. pigtails, yellow/ } \\
\text { blonde hair); description of boy (e.g. blue t-shirt); hands up in the air; other } \\
\text { description (e.g. a sunny day) }\end{array}$ & $\begin{array}{l}1 \text { point } \\
\text { each item }\end{array}$ \\
\hline & Max. Sub total & 18 \\
\hline \multirow[t]{2}{*}{ Event/action Natural } & the tree broke; branch broke/cracked/about to break; other relevant event & $\begin{array}{l}1 \text { point } \\
\text { each item }\end{array}$ \\
\hline & Max. Sub total & 13 \\
\hline \multirow[t]{3}{*}{ Cat as agent } & in the tree/on the branch; stuck in the tree/branch; climbed/ran up a tree & $\begin{array}{l}1 \text { point } \\
\text { each item }\end{array}$ \\
\hline & $\begin{array}{l}\text { wobbled/nearly fell; drank (the milk) (or couldn't); ate (the food) (or } \\
\text { couldn't); tried to get/climb down }\end{array}$ & \\
\hline & Max. Sub total & $/ 7$ \\
\hline Boy/girl as agent & $\begin{array}{l}\text { were walking/went past the tree; lost their cat; saw/heard the cat; waving } \\
\text { hands; calling/shouting/talking to cat; holding (food, drink); got the cat some } \\
\text { food; (trying to) feed/offered/gave food to the cat; (trying to) feed/offered/gave } \\
\text { drink/milk to the cat; tried to get the cat (down); (tried to) climbed up the tree; }\end{array}$ & $\begin{array}{l}1 \text { point } \\
\text { each item }\end{array}$ \\
\hline
\end{tabular}


Other person as agent

Goals/desires/ thoughts

Cat as agent

Boy/girl as agent

Feelings Cat as agent

Boy/girl/other person as agent:

Plans Cat as agent

Boy/girl/other person as agent

Dialogue Cat as agent

Boy/girl as agent agent

Boy/girl as agent

Other person as agent

Reaction didn't have a ladder; obtained a ladder; climbed up a ladder; jumped down; obtained/called a parent (e.g. shouted to mum)

Max. Sub total

were walking/went past/to the tree; lost their cat/put cat in the tree; heard the 1 point cat; holding (food, drink); got the cat some food; (trying to) offered/gave food each item to the cat; (trying to) offered/gave drink/milk to the cat; (tried to) get the cat (down); (tried to) climbed up the tree; didn't have a ladder; obtained a ladder; climbed up a ladder; obtained/called another agent (e.g. fire brigade)

Max. Sub total

wanting to get/climb down; not wanting to climb down/move (e.g. she didn't 1 point want to move); wanting food or drink

Max. Sub total

each item

tried to help; want to feed (the cat)/the cat to eat/drink; want the cat to come 1 point down; want a pet; thought the cat might fall down

Max. Sub total

each item

scared/worried; upset; sad; thirsty; hungry; other appropriate feeling

1 point

each item

Max. Sub total

scared/worried; upset; sad; love/like; other appropriate feeling

16

1 point

each item

Max. Sub total

1 point

decisions - decided to climb up/down; methods - thought/know how to get down/ if . . . then . . .

Max. Sub total

each item

decisions - decided to climb up/down; decisions — decided to get help/ladder; methods - thought/know how to get down/ if . . . then . . .

Max. Sub total

response (e.g. 'miaw'); attempt (e.g., 'help'; 'can you get me down?'

1 point

each item

1 point each item

Max. Sub total

12

instructions to cat (e.g. 'come down'; 'move over', 'slide down here', 'jump'); 1 point response to cat (e.g. 'no'; 'you'll fall down'); offer food to cat (e.g. 'here's your each item food cat'); response/request to parent/other person (e.g. 'mum, the cat's stuck in the tree'); instruction/response to other child

Max. Sub total

other person response/request/instruction to cat; other person response/ 1 point request/instruction to child (e.g. 'I'll get him down'; 'he can stay in the tree') each item

Max. Sub total

didn't/couldn't/wouldn't get down; climbed/jumped down; fell (down) out of 1 point the tree; was down/out of the tree; (still/stuck) in the tree; climbed (back) up each item the tree; scratched

Max. Sub total

didn't/couldn't/wouldn't climb; didn't/couldn't/wouldn't get the cat down; 1 point got the cat down; jumped/climbed down; fell down; found cat; catch cat

each item Max. Sub total

$/ 7$ didn't/couldn't/wouldn't climb; didn't/couldn't/wouldn't get the cat down; 1 point couldn't come/help (\& reason); got the cat down; jumped/climbed down; fell each item down; catch cat

Max. Sub total $/ 7$ pat/cuddle the cat; take cat home/inside/to bed; cared/gave food/milk (after 1 point getting cat down) each item

Max. Sub total

13

TOTAL

Note: Each information item may be scored only once. That is, only novel information is scored, not repeated information. However, agents and objects (e.g. 'cat') may be scored in association with verbs in another scoreable context. 